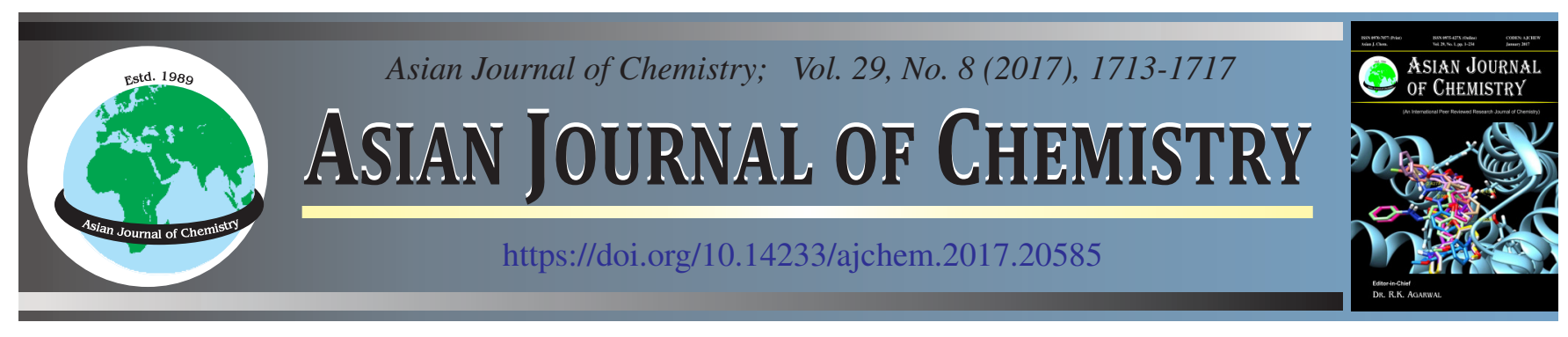

\title{
Targeted Metabolite Analysis of Iridoids of Paederia foetida: A Popular Tribal Edible Plant of Northeast, India
}

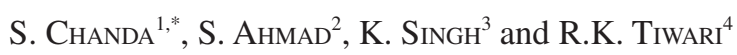

${ }^{1}$ Pharmacy Institute, Noida Institute of Engineering and Technology, 19, Knowledge Park-II, Institutional Area, Greater Noida-201306, India ${ }^{2}$ Department of Pharmacognosy and Phytochemistry, Jamia Hamdard, New Delhi-110 062, India

${ }^{3}$ Department of Chemistry, MMEC, Maharishi Markandeshwar University, Mullana-133 207, India

${ }^{4}$ Sunder Deep Pharmacy College, Dasna, Ghaziabad-201 015, India

*Corresponding author: E-mail: only_shilpi@yahoo.com

Received: 13 February 2017;

Accepted: 19 May 2017;

Published online: 12 June 2017;

AJC-18428

\begin{abstract}
Paederia foetida L., a wild edible plant used as a vegetable and medicine by the tribal people of India, produces iridoids. Taking into account the health benefits of iridoids, here we proposed a simple, economical, most dependable, moreover practically approachable method for the simultaneous estimation of iridoids from the extract of $P$. foetida. HPTLC method was developed and validated as per ICH guidelines. The developed HPTLC system includes the separation on pre-coated silica gel $60 \mathrm{~F} 254$ aluminium sheets with a solvent system chloroform, methanol and formic acid in a ratio of 8:2.5:0.1 ( $/ / \mathrm{v} / \mathrm{v})$ as mobile phase and quantitative densitometric scan done by absorbance measurement at $245 \mathrm{~nm}$. The system produces compact spots of the asperuloside and paederoside at $R_{\mathrm{f}}$ values of 0.56 and 0.65 , respectively. The linearity was found to be in the range of 400-3000 ng/spot for both with respect to peak area. The limits of detection and quantification values were found to be 121.23 and $363.69 \mathrm{ng} / \mathrm{spot}$, respectively for asperuloside and 94.11 and 228.33 $\mathrm{ng} / \mathrm{spot}$, respectively for paederoside. Recovery values 98 to $99 \%$ for both the reference standards indicate the excellent accuracy of the method. This method could be recommended as an analytical tool for quantification, quality control and also in herbal formulation which contains iridoids.
\end{abstract}

Keywords: Asperuloside, Densitometry, Iridoids, Paederia foetida, Paederoside.

\section{INTRODUCTION}

Out of 1600 plant species are used in Indian traditional systems of medicine; more than $80 \%$ are practiced in northeast India alone as ethnomedicine which indicating the rich traditional knowledge systems of that area. Such mastery of the tribe if studied scientifically might lighten not only the knowledge of medicinal prevention, but also to understand the nutritional importance and value of the use of wild products. One such plant is Paederia foetida L. belonging to the family Rubiaceae. Several literatures reported its therapeutic claim as anti diarrhoel [1], hepatoprotective and anti-inflammatory [2-4], antitussive [5], in rheumatoid arthritis [6] etc. Different community of tribal peoples of north-eastern India use this plant as vegetables [7-11] and worked well against different digestive problems [7] to treat different ailment including gastric trouble [9], to clean stomach, against stomach swelling [9], diarrhoea and dysentery [9,11-13], gastritis [10,14-16], ulceration [17], antidiabetic [18], etc. The most important active constituents, produced by $P$. foetida are iridoid glycosides namely asperuloside, paederoside (Fig. 1) and scandoside which are nothing but optically active cyclo-pentanoid monoterpene and mostly impart the defensive mechanism to the plant. The literature supports enormous therapeutic values of iridoids viz. analgesic, antidiabetic, antioxidant, antiinflammatory, antitumor, immunomodulatory, in ankle sprain, rheumatoid arthritis, hepatoprotective, inhibition of LDLoxidation, etc. [19-25]. Certain ethnic community of Orissa state of India cooks the leaves with rice to cure different joint diseases like rheumatism and gout [26].

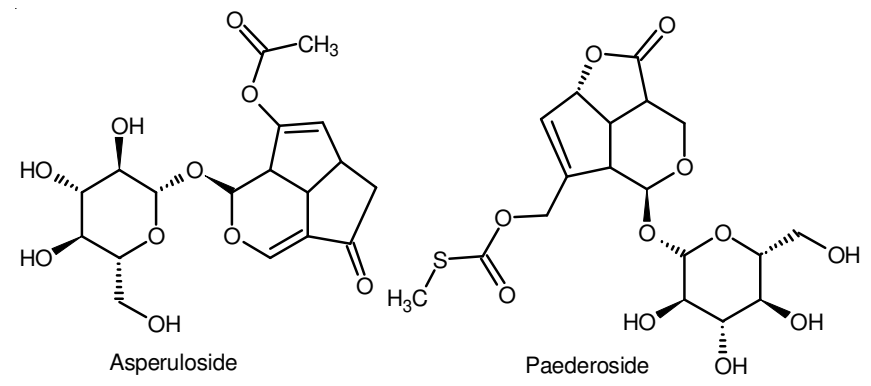

Fig. 1. Structure of asperuloside and paederoside 
Due to its various therapeutic effects a number of ayurvedic and herbal formulations are available in the market, namely Maha Narayan Oil, Sudard, Prasarani leha, Kubja prasarani taila, Rhue capsule (Ban lab, Mumbai), Dasamularista, prasarani taila etc. which contain Paederia as one of the ingredients. Therefore, it is becoming more important and urgent to evaluate an analytical method for the estimation of these glycosides. Moreover in the current scenario most of the Government and private Universities and organization giving emphasis to explore the unexplored plant species of the Northeastern part of India rather than the extensively explored ones. There are several literature published on iridoids mainly covering the extraction, isolation process and their characterization. To our best of knowledge till date there is no procedure for simultaneous estimation of these two iridoids. For estimation, the use of HPTLC system is becoming more simple and convenient in the context of cost and derivatization when compared to HPLC and GC, respectively. Moreover separation and identification of asperuloside and paederoside using GC-MS technique was unsuccessful because the TMS-derivatives of these iridoids exhibited different retention times, with the same fragmentation pattern [27]. Keeping these things in mind the current study was designed to develop and validate a rapid, simple, accurate, cost efficient, most dependable analytical method for separation and simultaneous estimation of iridoids viz. asperuloside and paederoside in $P$. foetida $\mathrm{L}$. which can be applied in other plants too.

\section{EXPERIMENTAL}

The aerial part (stem and leaf) of Paederia foetida L. was collected from the local tribal dominated market of Agartala, Tripura and the prepared herbarium was submitted to the National Institute of Science Communication and Information Resources, New Delhi (authentication reference no. NISCAIR/ RHMD/Consult/2010-11/1442/40) for authentication. Asperuloside (98.47\% pure) and paederoside (98.12\% pure) standards were purchased from WUXI App Tech (Tianjin) Co. Ltd. China whereas chloroform, methanol and formic acid were used of analytical grade and purchased from Merck Chemicals, India.

\section{Sample preparation}

Preparation of Paederia foetida extract: Petroleum ether wash was given to $500 \mathrm{mg}$ of leaf powder and then macerated with $5 \mathrm{~mL}$ of methanol overnight, followed by $30 \mathrm{~min}$ of sonication. The extract obtained was filtered and dried under the flow of nitrogen gas and dissolved in $1 \mathrm{~mL}$ of HPLC grade methanol and subjected to $0.22 \mu \mathrm{m}$ syringe filter (Millipore Corp., Bedford, MA, USA).

Preparation of standard solutions: Stock standard solution of asperuloside and paederoside were prepared individually by dissolving the same in HPLC grade methanol. In both the cases obtained concentration was $1000 \mu \mathrm{g} / \mathrm{mL}$ and used to prepare other working standards.

Chromatographic condition and preparation of calibration curve: We used a Camag Linomat V HPTLC system (Switzerlad) equipped with $100 \mu \mathrm{L}$ Camag syringe and scanner III. The samples were streaked in the form of narrow bands of width $3 \mathrm{~mm}$ with camag microlitre syringe on precoated silica gel aluminium plate $60 \mathrm{~F}-254(20 \times 10 \mathrm{~cm}$ with $0.2 \mathrm{~mm}$ of thickness, E. Merck, Germany) keeping a constant space between every band of $7.2 \mathrm{~mm}$ by using a nitrogen aspirator. A constant dosage speed of $150 \mathrm{~nL} / \mathrm{s}$ was maintained. The slit dimension was kept at $3 \times 0.1 \mathrm{~mm}$. A linear ascending development was carried out in Camag twin trough glass chamber which was lined with filter paper and pre-saturated with $30 \mathrm{~mL}$ mobile phase composed of chloroform, methanol and formic acid at a ratio of 8:2.5:0.1 $(\mathrm{v} / \mathrm{v} / \mathrm{v})$ for $20 \mathrm{~min}$ and the chromatogram was developed up to the length of $80 \mathrm{~mm}$. The developed TLC plates were dried in current of hot air. Densitometric scanning was performed on Camag TLC scanner III in the absorbance mode at $245 \mathrm{~nm}$ and operated by winCATS planar chromatography version 1.1.3.0. Concentrations of the compound chromatographed were determined from the intensity of diffusely reflected light. An evaluation was done via peak areas with linear regression. The whole analysis was performed in an air-conditioned room (temp. 22 $\pm 2{ }^{\circ} \mathrm{C}$ and RH $55 \pm 5 \%$ ). Absorption/remission was the measurement mode at a scan speed of $20 \mathrm{~mm} / \mathrm{s}$. Spots of asperuloside and paederoside were scanned from 200 to $400 \mathrm{~nm}$ to record their UV spectrum and to obtain their wavelengths of maximum absorption. HPTLC densitogram was recorded for whole extract (Fig. 2) and also for the reference standards at $245 \mathrm{~nm}$ (Fig. 3). The calibration curve for asperuloside and paederoside was investigated over a wide concentration range. The data of peak areas plotted against the corresponding concentrations were treated by least-square regression analysis (Figs. 4 and 5).

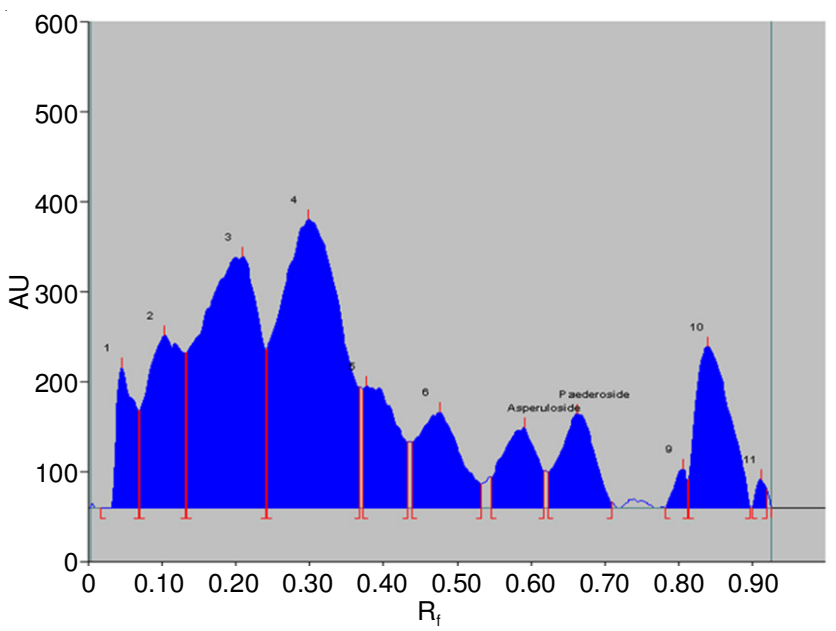

Fig. 2. HPTLC densitogram of $P$. foetida L. extract at $245 \mathrm{~nm}$

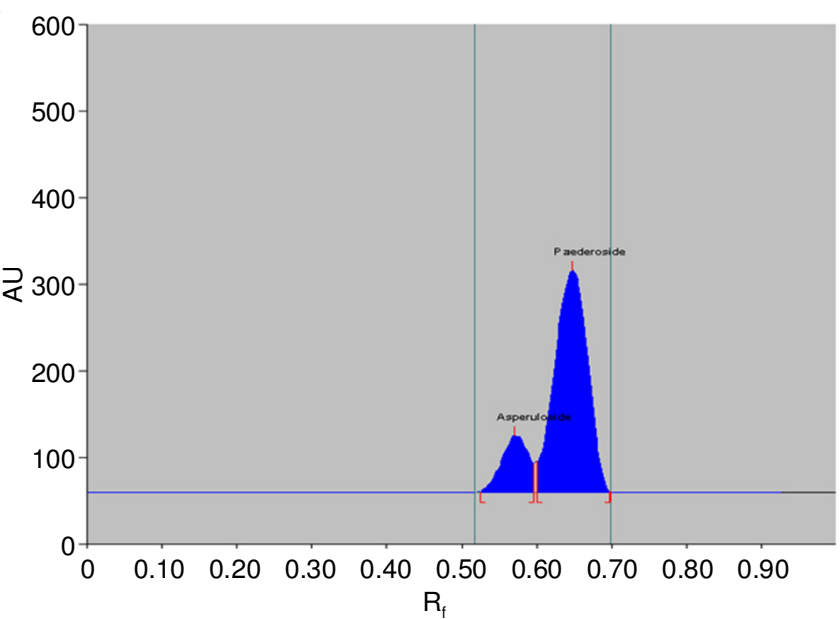

Fig. 3. HPTLC densitogram of asperuloside and paederoside at $245 \mathrm{~nm}$ 

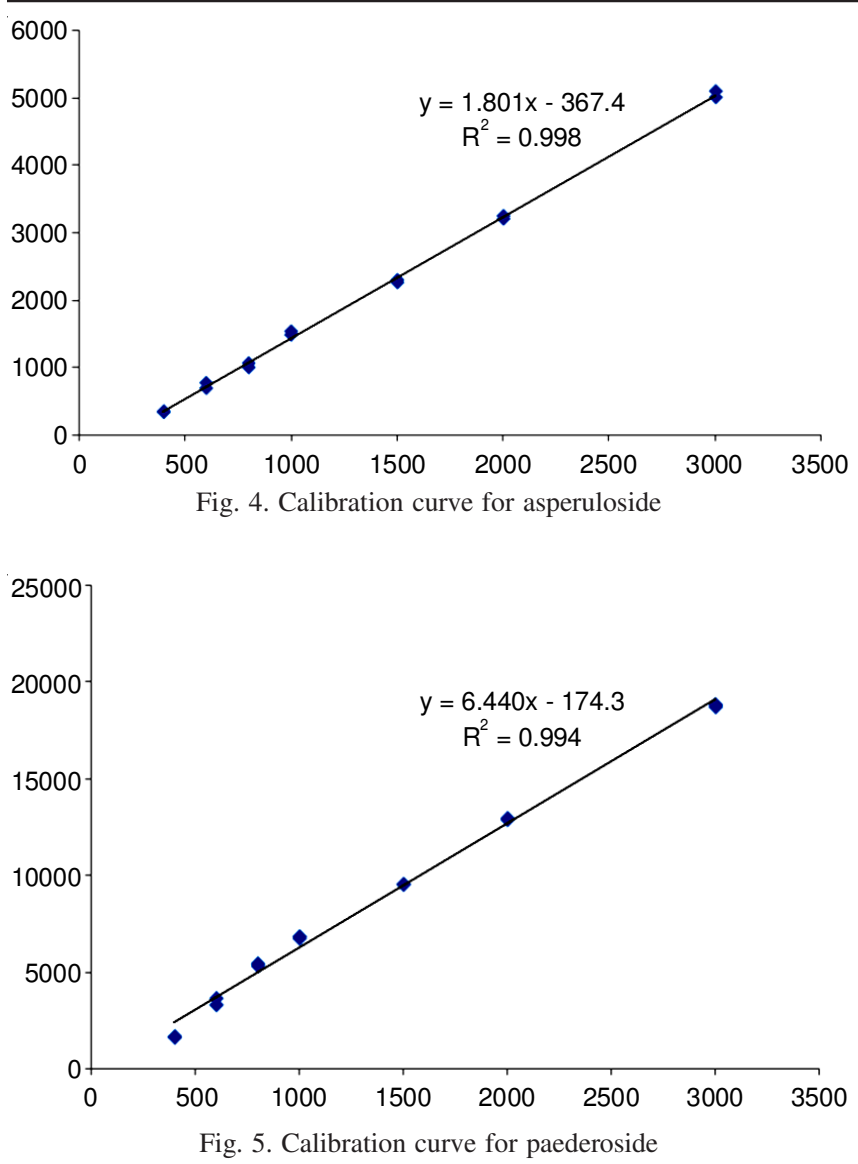

Method validation: The method was validated according to the ICH guidelines $[28,29]$ and the statistical analysis was done using Excel 2000 (MS Office). The specificity of the method was ascertained by analyzing standards and sample. The spots for asperuloside and paederoside in sample were confirmed by comparing the $\mathrm{R}_{\mathrm{f}}$ values and spectra of the spot in sample with those of standards. The peak purity of the sample was judged by comparing the spectra at peak start, peak apex and peak end positions of the spot (Figs. 6 and 7). Linearity was determined by applying spots of standard ( 0.4 to $8 \mu \mathrm{L}$ ) at about 6 different concentrations (400-3000 ng/spot) of 5 replicates that span between $50-200 \%$ of the expected working range. Accuracy of the analytical method was determined from recovery studies at four levels $(0,50,100$ and $150 \%)$ in triplicate by adding a known amount of analyte in the extract and the mixtures were re-analyzed by the same proposed method which was to be validated and calculated the spike recovery. The repeatability of HPTLC instruments was assessed by applying the same sample solution $(n=6)$ on a plate with the automatic spotter using the same syringe and by taking six scans of the sample spot for asperuloside and paederoside without changing the position of the plate. The intermediate precision of the method was studied by analyzing aliquots of standard in triplicate covering low $(600 \mathrm{ng} / \mathrm{spot})$, medium $(800$ $\mathrm{ng} / \mathrm{spot})$ and higher (1000 ng/spot) concentration levels for both the standards on the same day for Intraday precision. The study was also repeated on different days and by the different analysts with freshly prepared samples in order to determine Inter day precision. The results were expressed as \% RSD. The robustness of the method was determined by introducing

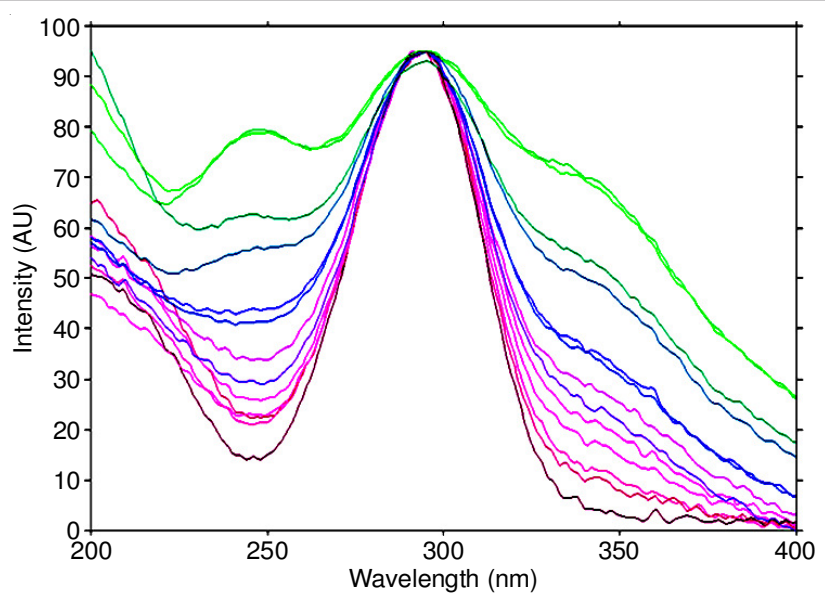

Fig. 6. Overlaid spectra of peak purity of reference asperuloside and sample

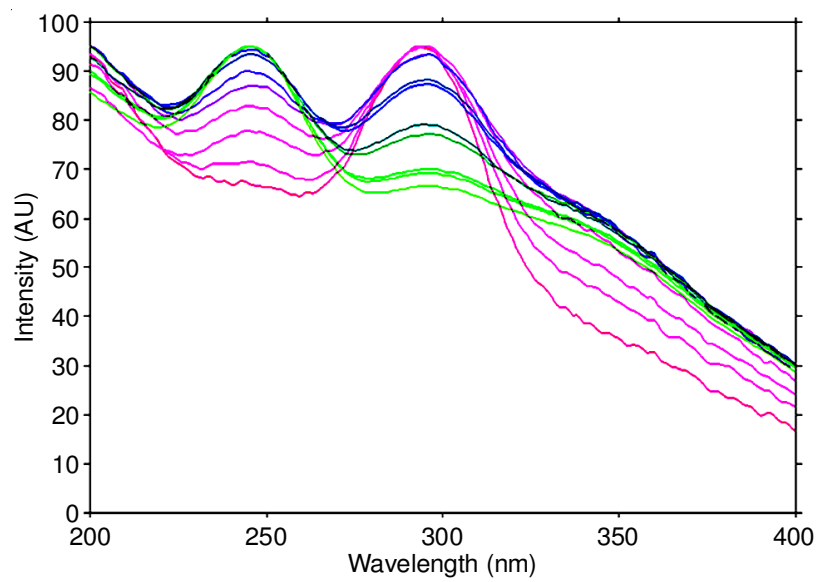

Fig. 7. Overlaid spectra of peak purity of reference paederoside and sample

small deliberate changes in certain chromatographic parameters such as alteration in the mobile phase composition (chloroform:methanol:formic acid 7.9:2.6:0.1, 8:2.5:0.1 and 8.1:2.4:0.1, v/v/v) and scanning wavelength $(243,245$ and 247 $\mathrm{nm}$ ) for both asperuloside and paederoside. In order to estimate the limit of detection (LOD) and the limit of quantification (LOQ), different dilutions of the standard solution of asperuloside and paederoside were applied, along with chloroform : methanol: formic acid $(8: 2.5: 0.1, \mathrm{v} / \mathrm{v} / \mathrm{v})$ as the blank.

\section{RESULTS AND DISCUSSION}

Initially as per the review of literature, several solvent systems, especially for iridoids, were tried and finally satisfactory resolution with compact spot and sharp and welldefined-resolved symmetric band of asperuloside $\left(R_{f} 0.56\right)$ and paederoside $\left(R_{f} 0.65\right)$ (Fig. 3) were obtained by using the mobile phase chloroform: methanol: formic acid (8:2.5:0.1 v/ $\mathrm{v} / \mathrm{v})$. As per ICH guidelines the developed method was validated in terms of accuracy, precision, repeatability, robustness and other validation parameter. Under the experimental conditions described above, the relationship between the concentration of standard solutions and the peak responses were linear (Table-1) and within the concentration range of 400-3000 ng/spot with a correlation coefficient of 0.998 for asperuloside and 0.994 for paederoside. Figs. 4 and 5 represents a linear curve of asperuloside and paederoside, respectively. As shown in Table-2 good recoveries of the substances, i.e. 98 


\begin{tabular}{|c|c|c|}
\hline \multicolumn{3}{|c|}{$\begin{array}{l}\text { TABLE-1 } \\
\text { LINEAR REGRESSION DATA FOR THE CALIBRATION PLOT } \\
(\mathrm{n}=3) \text { OF STANDARD ASPERULOSIDE AND PAEDEROSIDE }\end{array}$} \\
\hline & Asperuloside & Paederoside \\
\hline Linearity range & $400-3000 \mathrm{ng} / \mathrm{spot}$ & $400-3000 \mathrm{ng} / \mathrm{spot}$ \\
\hline Regression equation & $y=1.801 x-369.1$ & $y=6.440 x-174.3$ \\
\hline Correlation coefficient & 0.998 & 0.994 \\
\hline Slope & 1.801 & 6.44 \\
\hline Intercept & 369.1 & 174.3 \\
\hline
\end{tabular}

to $99 \%$ for both the standards were obtained when spiked with standard at four different concentration levels. The $\%$ RSD values with theoretical content are tabulated in Table- 2 . The HPTLC method was found to give repeatable results at three different concentrations $(600,800,1000 \mathrm{ng} / \mathrm{spot})$ showing the same $R_{\mathrm{f}}$ value and thereby the method is found to be reliable. The \% RSD tabulated in Table-3. Table-4 summarized the Intra-Inter-day and Inter analyst precision. There were insignificant variations in the peak areas (Table-4). The LOD and LOQ were found to be 121.23 and $363.69 \mathrm{ng} / \mathrm{spot}$, respectively, for asperuloside and 94.11 and $228.33 \mathrm{ng} / \mathrm{spot}$ for paederoside. During robustness studies, the $\%$ RSD was $<2 \%$ in each case. Table-5 showed the low values of \% RSD which
TABLE-4

PRECISION OF THE METHOD ( $\mathrm{n}=3$ ) DETERMINED BY HPTLC

\begin{tabular}{|c|c|c|c|c|}
\hline Standard & $\begin{array}{c}\text { Concentration } \\
\text { (ng/spot) }\end{array}$ & Peak area & SD & $\operatorname{RSD}(\%)$ \\
\hline \multicolumn{5}{|c|}{ Inter-day } \\
\hline \multirow{3}{*}{ Asperuloside } & 600 & 721.97 & 14.27 & 1.98 \\
\hline & 800 & 1072.89 & 10.13 & 0.94 \\
\hline & 1000 & 1453.15 & 19.22 & 1.32 \\
\hline \multirow{3}{*}{ Paederoside } & 600 & 3668.28 & 40.18 & 1.10 \\
\hline & 800 & 4960.64 & 35.04 & 0.71 \\
\hline & 1000 & 6234.38 & 28.82 & 0.46 \\
\hline \multicolumn{5}{|c|}{ Intra-day } \\
\hline \multirow{3}{*}{ Asperuloside } & 600 & 718.62 & 11.96 & 1.66 \\
\hline & 800 & 1061.25 & 7.82 & 0.74 \\
\hline & 1000 & 1448.75 & 18.95 & 1.31 \\
\hline \multirow{3}{*}{ Paederoside } & 600 & 3648.85 & 44.95 & 1.23 \\
\hline & 800 & 4960.41 & 27.27 & 0.55 \\
\hline & 1000 & 6229.47 & 30.50 & 0.49 \\
\hline \multicolumn{5}{|c|}{ Inter-analyst } \\
\hline \multirow{3}{*}{ Asperuloside } & 600 & 716.85 & 13.69 & 1.91 \\
\hline & 800 & 1069.73 & 11.57 & 1.08 \\
\hline & 1000 & 1453.09 & 20.39 & 1.40 \\
\hline \multirow{3}{*}{ Paederoside } & 600 & 3669.92 & 14.83 & 0.40 \\
\hline & 800 & 4909.57 & 64.69 & 1.32 \\
\hline & 1000 & 6256.60 & 25.05 & 0.40 \\
\hline
\end{tabular}

TABLE-2

RECOVERY STUDIES FOR DETERMINATION OF ACCURACY $(\mathrm{n}=3)$ IN PRE-ANALYZED SAMPLES DETERMINED BY HPTLC

\begin{tabular}{ccccccc}
\hline Substance & $\begin{array}{c}\text { Amount }(\%) \text { of standard } \\
\text { spiked in sample }\end{array}$ & $\begin{array}{c}\text { Theoretical content } \\
(\mathrm{ng} / \mathrm{spot})\end{array}$ & $\begin{array}{c}\text { Amount of substance } \\
\text { recovered (ng/spot) }\end{array}$ & SD & $\begin{array}{c}\text { Substance } \\
\text { recovered (\%) }\end{array}$ & RSD (\%) \\
\hline \multirow{4}{*}{ Asperuloside } & 0 & 455 & 452.89 & 3.65 & 99.54 & 0.81 \\
& 50 & 682.5 & 678.77 & 5.02 & 99.45 & 0.74 \\
& 100 & 910 & 903.86 & 6.35 & 99.33 & 0.70 \\
Paederoside & 150 & 1137.5 & 1122.59 & 13.97 & 98.69 & 1.24 \\
& 0 & 390 & 385.92 & 4.01 & 98.95 & 1.04 \\
& 50 & 585 & 577.34 & 6.99 & 98.69 & 1.21 \\
& 100 & 980 & 774.22 & 5.23 & 99.26 & 0.68 \\
\hline
\end{tabular}

TABLE-3

REPEATABILITY OF THE METHOD $(n=6)$

\begin{tabular}{|c|c|c|c|c|c|c|c|}
\hline Standard & $\begin{array}{l}\text { Concentration } \\
\text { (ng/spot) }\end{array}$ & Peak area & SD & RSD (\%) & $\mathrm{R}_{\mathrm{f}}$ & $\mathrm{SD}$ & $\operatorname{RSD}(\%)$ \\
\hline \multirow{3}{*}{ Asperuloside } & 600 & 726.21 & 9.43 & 1.30 & 0.56 & 0.01 & 0.92 \\
\hline & 800 & 1063.07 & 15.38 & 1.45 & 0.56 & 0.00 & 0.73 \\
\hline & 1000 & 1430.12 & 19.29 & 1.35 & 0.56 & 0.01 & 0.92 \\
\hline \multirow{3}{*}{ Paederoside } & 600 & 3644.99 & 33.72 & 0.93 & 0.65 & 0.00 & 0.63 \\
\hline & 800 & 4939.41 & 30.91 & 0.63 & 0.65 & 0.01 & 1.16 \\
\hline & 1000 & 6262.32 & 31.54 & 0.50 & 0.65 & 0.01 & 1.38 \\
\hline
\end{tabular}

TABLE-5

ROBUSTNESS OF HPTLC METHOD $(\mathrm{n}=3)$

\begin{tabular}{|c|c|c|c|c|c|}
\hline Standard & Parameter & Used levels & Peak area & $\mathrm{SD}$ & RSD (\%) \\
\hline \multirow{3}{*}{ Asperuloside } & \multirow{3}{*}{$\begin{array}{l}\text { Chloroform:methanol:formic } \\
\text { acid (v/v/v) }\end{array}$} & 7.9:2.6:0.1 & 1414.04 & 8.21 & 0.58 \\
\hline & & $8: 2.5: 0.1$ & 1426.60 & 12.14 & 0.85 \\
\hline & & $8.1: 2.4: 0.1$ & 1427.33 & 8.49 & 0.59 \\
\hline \multirow{3}{*}{ Paederoside } & \multirow{3}{*}{$\begin{array}{l}\text { Chloroform:methanol:formic } \\
\text { acid (v/v/v) }\end{array}$} & 7.9:2.6:0.1 & 6265.47 & 35.35 & 0.56 \\
\hline & & $8: 2.5: 0.1$ & 6278.10 & 27.93 & 0.44 \\
\hline & & $8.1: 2.4: 0.1$ & 6281.97 & 24.87 & 0.40 \\
\hline \multirow{3}{*}{ Asperuloside } & \multirow{3}{*}{ Scanning wavelength (nm) } & 243 & 1439.88 & 12.50 & 0.87 \\
\hline & & 245 & 1432.57 & 13.53 & 0.94 \\
\hline & & 247 & 1448.97 & 19.27 & 1.33 \\
\hline \multirow{3}{*}{ Paederoside } & \multirow{3}{*}{ Scanning wavelength (nm) } & 243 & 6268.03 & 44.32 & 0.71 \\
\hline & & 245 & 6321.03 & 33.43 & 0.53 \\
\hline & & 247 & 6316.10 & 23.00 & 0.36 \\
\hline
\end{tabular}


represents the robustness of the method. The specificity of the analytes was checked by checking the peak purity or by checking the resolution when mixed with the other related compounds. The spot of asperuloside and paederoside was confirmed by comparing the $\mathrm{R}_{\mathrm{f}}$ value and spectra of the sample with respect to standards. $0.12 \% \mathrm{w} / \mathrm{w}$ asperuloside and $0.097 \% \mathrm{w} / \mathrm{w}$ of paederoside present in the extract was determined from the regression equation.

\section{Conclusion}

The most important key of this article is the first time proposed validated HPTLC method for quantitative simultaneous estimation of two iridoids viz. asperuloside and paederoside which can also be used in raw materials as well. The method is accurate, precise, linear, rugged, specific, simple, rapid and within the range. As there are several herbal formulations available in the market containing iridoids (asperuloside and paederoside) as one of the ingredients or paederia, this method could be used for routine quality control purpose for those polyherbal formulations and also act as an alternative method where slower and more costly GC and HPLC methods are showing limitations. Hence the present HPTLC method is suitable for the quality control of the raw materials, extracts and assay of the two iridoids in extract or in herbal formulations.

\section{ACKNOWLEDGEMENTS}

The authors are thankful to Mr. Ennus Tamboli, Jamia Hamdard, New Delhi, India for his continuous support in handling the HPTLC instrument.

\section{REFERENCES}

1. S. Afroz, M. Alamgir, M.T.H. Khan, S. Jabbar, N. Nahar and M.S.K. Choudhuri, J. Ethnopharmacol., 105, 125 (2006); https://doi.org/10.1016/j.jep.2005.10.004.

2. M.C. Srivastava, J.P. Tewari and V. Kant, Indian J. Med. Sci., 27, 231 (1973).

3. S. De, B. Ravishankar and G.C. Bhavsar, Indian J. Nat. Prod., 9, 7 (1993).

4. S. De, B. Ravishankar and G.C. Bhavsar, J. Ethnopharmacol., 3, 1 (1994)

5. G. Nosalova, J. Mokry, A. Ather and M.T.H. Khan, Acta Vet. Brno, 76, 27 (2007); https://doi.org/10.2754/avb200776010027.

6. N. Rajashekhara, P.P. Sharma and P. Vasant, $A Y U, \mathbf{3 0}, 503$ (2009).

7. T.R. Sarmah, D. Adhikari, M. Majumdar and A. Arunachalan, Indian J. Tradit. Knowl., 7, 587 (2008).

8. S. Chanda, B. De and R.K. Tiwari, in eds.: M.D. Choudhury, G.D. Sharma, S. Choudhury and A.D. Talukdar, In: Status and Conservation of Biodiversity in North East India, Swastik Publications, Delhi, pp 118-124 (2011).
9. R.C. Srivastava and R.K. Singh, Indian J. Tradit. Knowl., 9, 432 (2010).

10. A. Kar and S.K. Borthakur, Nat. Prod. Radiance, 7, 448 (2008).

11. R. Kagyung, P.R. Gajurel, P. Rethy and B. Singh, Indian J. Tradit. Knowl., 9, 496 (2010).

12. P.K. Borah, P. Gogoi, A.C. Phukan and J. Mahanta, Indian J. Tradit. Knowl., 5, 510 (2006).

13. S.K. Basumatary, M. Ahmed and S.P. Deka, Nat. Prod. Radiance, 3, 88 (2004).

14. S. Tangjang, N.D. Namsa, C. Aran and A. Litin, J. Ethnopharmacol., 134, 18 (2011); https://doi.org/10.1016/j.jep.2010.11.053.

15. C.P. Kala, J. Ethnobiol. Ethnomed., 1, 11 (2005); https://doi.org/10.1186/1746-4269-1-11.

16. N.L. Pfoze, Y. Kumar and B. Myrboh, Phytopharmacology, 2, 285 (2012).

17. S. Chanda, I.P. Sarethy, B. De and K. Singh, J. For. Res., 24, 801 (2013); https://doi.org/10.1007/s11676-013-0369-2.

18. D.R. Chhetri, P. Parajuli and G.C. Subba, J. Ethnopharmacol., 99, 199 (2005); https://doi.org/10.1016/j.jep.2005.01.058.

19. M. Liu, L. Zhou, Z. Chen and C. Hu, Pharmacol. Biochem. Behav., 102, 465 (2012); https://doi.org/10.1016/j.pbb.2012.06.007

20. Y.F. Chen, N. Li, Y.L. Jiao, P. Wei, Q.Y. Zhang, K. Rahman, H.C. Zheng and L.P. Qin, Phytomedicine, 15, 427 (2008); https://doi.org/10.1016/j.phymed.2007.09.023.

21. T. Miura, Y. Nishiyama, M. Ichimaru, M. Moriyasu and A. Kato, Biol. Pharm. Bull., 19, 160 (1996); https://doi.org/10.1248/bpb.19.160.

22. W. Zhu, M. Pang, L. Dong, X. Huang, S. Wang and L. Zhou, Life Sci., 91, 369 (2012); https://doi.org/10.1016/j.1fs.2012.08.013.

23. H.K. Hamdi and R. Castellon, Biochem. Biophys. Res. Commun., 334, 769 (2005); https://doi.org/10.1016/j.bbrc.2005.06.161.

24. Q.C. Chen and W.Y. Zhang, U. Youn, H. Kim, I. Lee, H.J.Jung, M. Na, B.S. Min and K. Bae, Phytochemistry, 70, 779 (2009); https://doi.org/10.1016/j.phytochem.2009.03.008.

25. D.H. Kim, H.J. Lee, Y.J. Oh, M.J. Kim, S.H. Kim, T.S. Jeong and N.I. Baek, Arch. Pharm. Res., 28, 1156 (2005); https://doi.org/10.1007/BF02972979.

26. H. Singh, G. Krishna and P.K. Baske, Report and Opinion, 2 (2010).

27. H. Inouye, K. Uobe, M. Hirai, Y. Masada and K. Hashimoto, J. Chromatogr. A, 118, 201 (1976); https://doi.org/10.1016/S0021-9673(00)81209-1.

28. ICH, Text on Validation of Analytical Procedures, Harmonised Tripartite Guideline prepared within the International Conference on Harmonisation of Technical requirements for the Registration of Pharmaceuticals for Human Use, ICH-Q2A, Geneva (1994).

29. ICH, Validation of Analytical Procedures: Methodology, Harmonised Tripartite Guideline prepared within the International Conference on Harmonisation of Technical Requirements for the Registration of Pharmaceuticals for Human Use, ICH-Q2B, Geneva (1996). 